\title{
Influence of Quenching and Partitioning Parameters on Phase Transformations and Mechanical Properties of Medium Manganese Steel for Press-Hardening Application
}

\author{
Charline Blankart *, Sebastian Wesselmecking and Ulrich Krupp
}

check for

updates

Citation: Blankart, C.;

Wesselmecking, S.; Krupp, U.

Influence of Quenching and

Partitioning Parameters on Phase

Transformations and Mechanical

Properties of Medium Manganese

Steel for Press-Hardening Application.

Metals 2021, 11, 1879. https://

doi.org/10.3390/met11111879

Academic Editor: Mohamed Soliman

Received: 4 November 2021

Accepted: 19 November 2021

Published: 22 November 2021

Publisher's Note: MDPI stays neutral with regard to jurisdictional claims in published maps and institutional affiliations.

Copyright: (c) 2021 by the authors. Licensee MDPI, Basel, Switzerland. This article is an open access article distributed under the terms and conditions of the Creative Commons Attribution (CC BY) license (https:// creativecommons.org/licenses/by/ $4.0 /)$.
Steel Institute, RWTH Aachen University, 52072 Aachen, Germany; sebastian.wesselmecking@iehk.rwth-aachen.de (S.W.); krupp@iehk.rwth-aachen.de (U.K.)

* Correspondence: charline.blankart@iehk.rwth-aachen.de; Tel.: +49-241-80-95824
Abstract: It has been proven that through targeted quenching and partitioning ( $\mathrm{Q} \& \mathrm{P})$, medium manganese steels can exhibit excellent mechanical properties combining very high strength and ductility. In order to apply the potential of these steels in industrial press hardening and to avoid high scrap rates, it is of utmost importance to determine a robust process window for $\mathrm{Q} \& \mathrm{P}$. Hence, an intensive study of dilatometry experiments was carried out to identify the influence of quenching temperature $\left(T_{Q}\right)$ and partitioning time $\left(t_{p}\right)$ on phase transformations, phase stabilities, and the mechanical properties of a lean medium manganese steel. For this purpose, additional scanning electron microscopy (SEM), electron backscatter diffraction (EBSD), and energy dispersive X-ray spectroscopy (EDX) examinations as well as tensile testing were performed. Based on the dilatometry data, an adjustment of the Koistinen-Marburger (K-M) equation for medium manganese steel was developed. The results show that a retained austenite content of $12-21 \%$ in combination with a low-phase fraction of untempered secondary martensite (max. 20\%) leads to excellent mechanical properties with a tensile strength higher than $1500 \mathrm{MPa}$ and a total elongation of $18 \%$, whereas an exceeding secondary martensite phase fraction results in brittle failure. The optimum retained austenite content was adjusted for $T_{Q}$ between $130^{\circ} \mathrm{C}$ and $150^{\circ} \mathrm{C}$ by means of an adapted partitioning.

Keywords: medium manganese steel; quenching and partitioning; dilatometry; martensitic phase transformation; press hardening

\section{Introduction}

The reduction in $\mathrm{CO}_{2}$ emissions is one of the most important issues in the automotive industry. One effective way of reducing emissions of passenger cars is to lower vehicle weight. The greatest potential for savings can be found in the area of autobody design, where, for example, high-strength steels are now replacing conventional deep drawing sheet material [1,2]. One of the most efficient processes for the production of high-strength crash-relevant components is press hardening, in which forming and hardening are combined in a single process step (direct press hardening) [3]. Currently, manganese-boron steels such as $22 \mathrm{MnB} 5$ or $20 \mathrm{MnB} 8$ are used for this purpose. In their initial state, these steels have a ferritic-pearlitic (FP) microstructure, which is completely transformed into martensite with tensile strengths of $1500 \mathrm{MPa}$ and higher by austenitizing and press hardening [4]. Alloying elements such as carbon, manganese, chromium, and boron increase the strength attainable by this process and, above all, suppress the diffusion-controlled FP transformation, which allows the critical cooling rate for the formation of martensite to be reduced to a technically feasible value of at least $27 \mathrm{~K} / \mathrm{s}$ [5]. However, the residual formability (approx. 7\%) is greatly reduced by the complete formation of martensite, which is why these components are only suitable to a limited extent for crash-relevant anti-intrusion areas of the car body. For this reason, tailoring methods such as tailored tempering with a partially heatable die [6] or tailored furnace modules for precise local 
heat treatment [7], as well as the use of third-generation advanced high-strength steels (AHSS) [8-11], are proceeding in the focus of research and development activities in the area of press hardening $[3,12-14]$.

Compared to 22MnB5, medium manganese steels can have a significantly lower critical cooling rate as well as lower transformation temperatures due to an adapted alloying concept. Consequently, this allows a more robust process control and, in addition, a significantly lower austenitization temperature. In comparison to manganese boron steels, the austenitization temperature of medium manganese steels can be lowered by $100-200^{\circ} \mathrm{C}$ [15], which is associated with considerably reduced energy consumption [16]. Furthermore, the lower austenitization temperature leads to a comparatively finer microstructure, which positively influences both the strength and the ductility of the material, respectively [17].

In addition, it is possible to set a multiphase microstructure consisting of a combination of hard and ductile phases through targeted temperature control during the press hardening process, which leads to an improved combination of strength and residual formability. One approach is to integrate quenching and partitioning $(\mathrm{Q} \& \mathrm{P})$ into the press hardening process. After austenitizing, the material is stamped within a temperature-controlled die and initially quenched to a temperature range between the martensite start temperature $M_{s}$ and the martensite finish temperature $M_{f}$ to partially produce fresh primary martensite $\left(\alpha_{\mathrm{FP}}^{\prime}\right)$. Partitioning subsequently occurs during annealing at temperatures between $M_{s}$ and $\mathrm{A}_{\mathrm{C} 1}$. At elevated temperatures, carbon and manganese diffuse from the martensite into the austenite, which leads to tempering of primary martensite and a stabilization of austenite and hence to retained austenite in the final microstructure after quenching to room temperature since $M_{f}$ dropped below room temperature (Figure 1) [18].

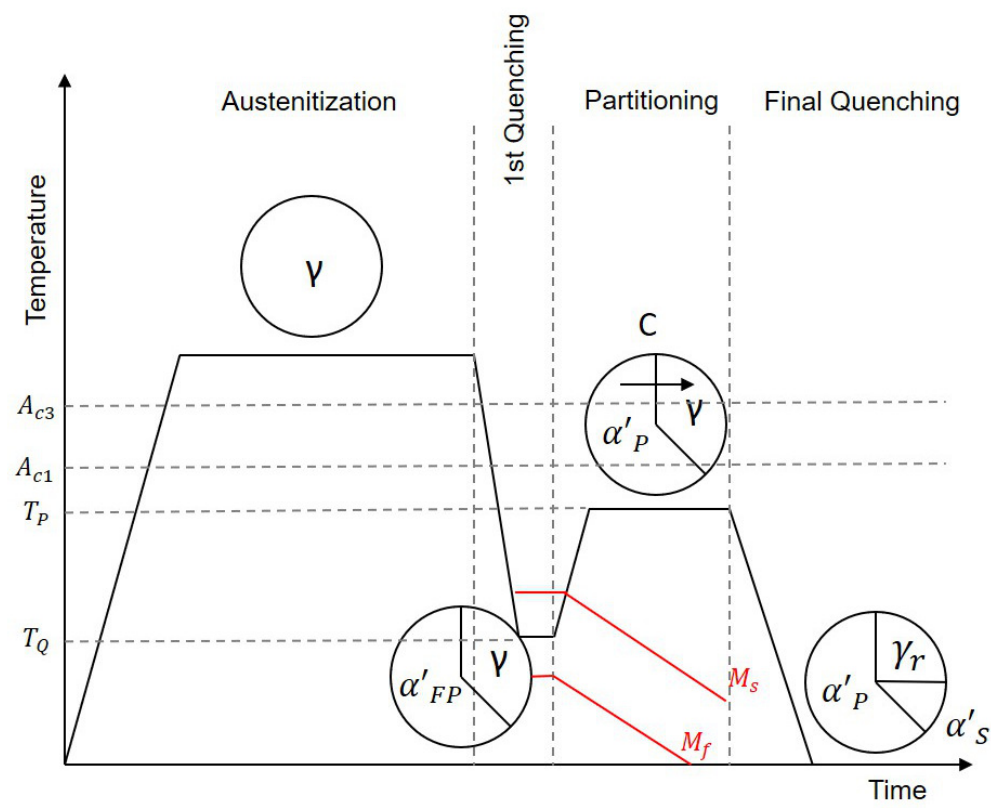

Figure 1. Schematic description of the $Q \& P$ process and the microstructural evolution during the heat treatment.

In sensitive dependence on the $\mathrm{Q} \& \mathrm{P}$ parameters, highly complex final microstructures of tempered primary martensite $\left(\alpha_{\mathrm{P}}^{\prime}\right)$, fresh secondary martensite $\left(\alpha_{\mathrm{S}}^{\prime}\right)$, and retained austenite $\left(\gamma_{\mathrm{r}}\right)$ are formed, whereby the mechanical properties can be precisely adjusted $[18,19]$. This has been proven, among others, by the investigations of de Cooman et al. [20] and de Moor et al. [21], who performed Q \& P treatments on medium manganese steels in a dilatometer and in salt baths, respectively, and achieved tensile strengths of $1500 \mathrm{MPa}$ at total elongation of $15 \%$. 
However, in industrial production, variations in the process parameters occur unregularly, which means that the exact control of the optimum heat treatment parameters cannot be guaranteed. In order to minimize possible scrap, the aim of this work was to determine a process window for quenching and partitioning treatment for a lean medium manganese steel that is as robust as possible, as well as to investigate how possible variations in quenching temperature can be compensated by adjusting the partitioning treatment. To achieve this, a precise knowledge of the phase transformation kinetics and phase stability as a function of the process parameters is of great importance. For this purpose, different series of dilatometer experiments were carried out, in which the quenching temperature and the partitioning time were varied, and the respective phase transformations were identified and quantified. Furthermore, the microstructure was characterized in detail and correlated with the mechanical properties from the tensile test.

\section{Materials and Methods}

For the experiments, an ingot of $80 \mathrm{~kg}$ (cross-section $140 \times 140 \mathrm{~mm}^{2}$ ) of a medium manganese steel with a nominal composition of $\mathrm{Fe}-0.3 \% \mathrm{C}-5 \% \mathrm{Mn}-1.5 \% \mathrm{Si}$ (wt. $\%$, details in Table 1) was produced by a laboratory vacuum-induction melting process. The ingot was homogenized at $1150^{\circ} \mathrm{C}$ for $2 \mathrm{~h}$ and subsequently forged to a cross-section of $120 \times 120 \mathrm{~mm}^{2}$ in a temperature range between $1150^{\circ} \mathrm{C}$ and $850^{\circ} \mathrm{C}$. This was followed by a second homogenization for $5 \mathrm{~h}$ at $1150^{\circ} \mathrm{C}$ and furnace cooling. The forged ingot was then hot-rolled to a thickness of $3 \mathrm{~mm}$, annealed at $650^{\circ} \mathrm{C}$ for $2 \mathrm{~h}$ and cold-rolled to a final thickness of $1.5 \mathrm{~mm}$.

Table 1. Chemical composition (in wt.\%) of the studied medium manganese steel.

\begin{tabular}{ccccccccc}
\hline Fe & $\mathbf{C}$ & $\mathbf{M n}$ & $\mathbf{S i}$ & $\mathbf{A l}$ & $\mathbf{C r}$ & $\mathbf{P}$ & $\mathbf{S}$ & $\mathbf{N}$ \\
\hline bal. & 0.30 & 4.99 & 1.55 & 0.004 & 0.04 & 0.005 & 0.003 & 0.004 \\
\hline
\end{tabular}

For a detailed understanding of the material's phase transformation behavior, THERMOCALC simulations with the TCFE9 database were performed. Dilatometer experiments were carried out using a BÄHR Dil 805 A/D dilatometer (TA instruments, Hüllhorst, Germany) in combination with specimens of a size of $7 \times 4 \times 1.5 \mathrm{~mm}^{3}$ cut from the cold-rolled sheet material. The $A_{c 1}$ and $A_{c 3}$ temperatures were determined at a heating rate of $0.05 \mathrm{~K} / \mathrm{s}$. The austenitization for the following experiments was then set at $\mathrm{A}_{\mathrm{c} 3}+60^{\circ} \mathrm{C}$ for a duration of $300 \mathrm{~s}$ to ensure fully austenitic microstructure before cooling. $M_{s}$ and $M_{f}$ were determined for the selected austenitization followed by cooling to room temperature using argon.

For the quenching and partitioning experiments, samples were first austenitized and immediately quenched to an intermedium temperature $T_{Q}$ between $M_{S}$ and $M_{f}$. After an isothermal holding time of $10 \mathrm{~s}$ at $T_{Q}$, in order to ensure an even heat distribution within the sample, the samples were heated to a partitioning temperature $T_{p}=400^{\circ} \mathrm{C}$ and held isothermally for $60 \mathrm{~s}$ before final quenching to room temperature.

The suitable range for $T_{Q}\left(130 / 150 / 170 / 190 / 210^{\circ} \mathrm{C}\right)$ was estimated by adapting the lever law to dilatation curves to determine the amount of formed primary martensite after initial quenching $\left(V_{m}\right)$, as well as by adjusting and rearranging the Koistinen-Marbuger (K-M) equation (Equation (1)) [22] $\left(V_{\gamma}=\right.$ phase fraction of austenite; $\alpha$ and $\beta=$ empirical parameters):

$$
\begin{gathered}
V_{\gamma}=\exp \left(-1.10 * 10^{-2}\left(M_{s}-T_{Q}\right)\right) \\
V_{m}=1-\exp \left(-\alpha\left(M_{s}-T_{Q}\right)^{\beta}\right)
\end{gathered}
$$

Within a second experimental series, $T_{Q}$ was set fixed to $150^{\circ} \mathrm{C}$ and $170{ }^{\circ} \mathrm{C}$ while the partitioning time $t_{P}(60 / 180 / 300 \mathrm{~s})$ was varied (Figure 2). In the following, the different quenched and partitioned states will be described as " $\mathrm{QPT}_{\mathrm{Q}-} \mathrm{t}_{\mathrm{P}}$ ". 


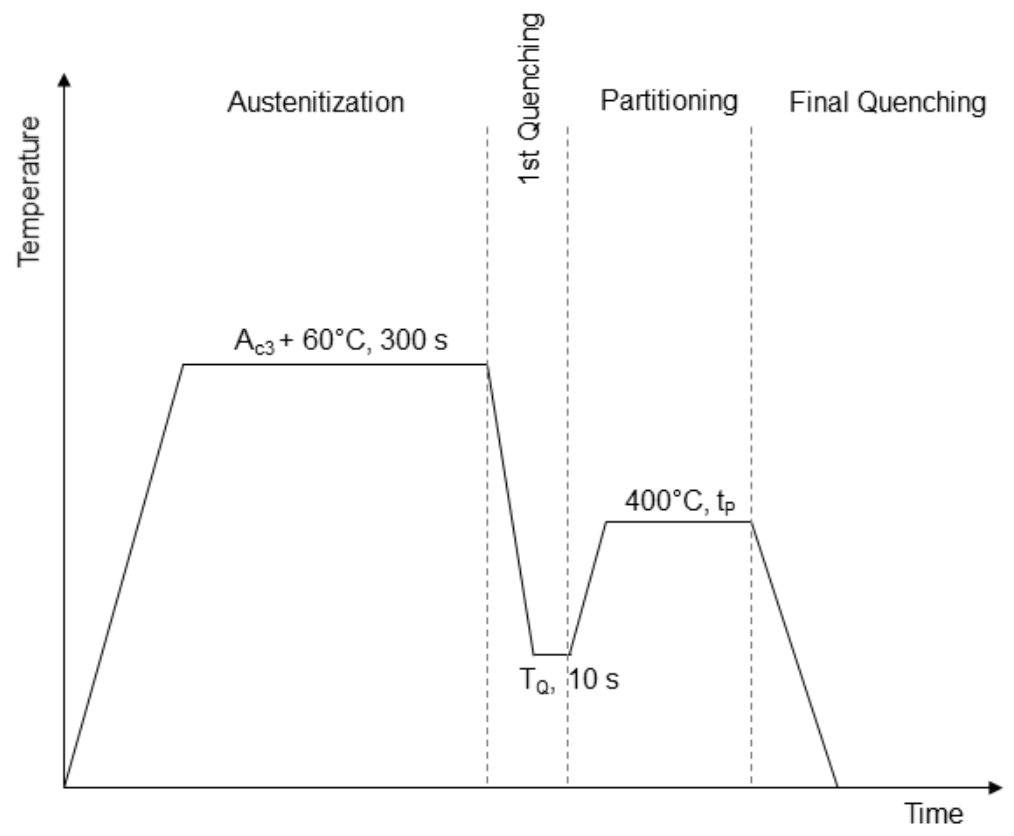

Figure 2. Schematic temperature-time diagram of the quenching and partitioning experiments for first (varying $T_{Q}$ and $t_{P}=60 \mathrm{~s}$ ) and second experimental series $\left(T_{Q}=150 / 170{ }^{\circ} \mathrm{C}\right.$ and varying $\left.t_{P}\right)$.

To determine the mechanical properties of the material, selected heat treatments were duplicated in salt baths on dog-bone-shaped tensile samples (A30, cut along rolling direction). Subsequent uniaxial tensile tests were performed with ZWICKROELL Z100 (ZwickRoell GmbH \& Co. KG, Ulm, Germany) at room temperature at a strain rate of $0.0005 / \mathrm{s}$ using an optical strain measurement with an accuracy class of 0.5 .

In order to analyze and quantify the phase transformation detected in the dilatometer, the microstructure was additionally investigated on $3 \% \mathrm{HNO}_{3}$ (Nital) etched samples by means of light optical microscopy (LOM) using KEYENCE VHX6800 (Keyence Corporation, Osaka, Japan) and scanning electron microscopy (SEM) in combination with energy-dispersive X-ray spectroscopy (EDX) using ZeISs Sigma field emission gun (Carl Zeiss AG, Oberkochen, Germany) with an acceleration voltage of $5-20 \mathrm{kV}$ and a working distance of $10 \mathrm{~mm}$ in combination with an OXFORD INSTRUMENTS X-MAX ${ }^{\mathrm{N}}$ EDX detector (Oxford Instruments plc, Abingdon, Great Britain) operating with OXFORD INSTRUMENTS AZTEC ${ }^{\circledR} 5.0$ software. Prior austenite grain size was determined on picric etched as-quenched samples. For estimation of the retained austenite content of different quenched and partitioned conditions, automated electron back-scatter diffraction (EBSD) measurements with an acceleration voltage of $20 \mathrm{kV}$, a working distance of $18 \mathrm{~mm}$, and a step size of $60 \mathrm{~nm}$ were carried out on electropolished samples using an OXFORD INSTRUMENTS NORDLYSNANO EBSD detector. The electropolishing was performed for $15 \mathrm{~s}$ at $17 \mathrm{~V}$ in STRUERS electrolyte A2 (Struers $\mathrm{GmbH}$, Willich, Germany). For determination of primary and secondary martensite fraction, image contrasting method by means of ImageJ $1.47 \mathrm{v}$ was applied on light-optical and scanning-electron micrographs. The results were additionally compared with the image quality (IQ) maps of EBSD measurements.

\section{Results and Discussion}

\subsection{Phase Transformations and Initial State}

Figure 3 represents the prediction of most stable phases by THERMOCALC simulation, whereas Figure 4 shows the experimental determined CCT diagram for Fe- $0.3 \% \mathrm{C}-5 \% \mathrm{Mn}-$ $1.5 \% \mathrm{Si}$. Next to the start $\left(\mathrm{Ac}_{1 \mathrm{~b}}\right)$ and finish $\left(\mathrm{Ac}_{3}\right)$ temperature of austenite formation, carbide solution was also identified during the heating of dilatometric samples. The completion of carbide solution was reached at $735^{\circ} \mathrm{C}\left(\mathrm{Ac}_{1 \mathrm{e}}\right)$. Additionally, the dilatometer experiments revealed that for the investigated medium manganese steel, the bainitic transformation was 
suppressed completely, even for slow cooling with $t_{8 / 5}>1 \mathrm{~h}$, due to the alloying concept with $5 \mathrm{wt} . \% \mathrm{Mn}$ and a relatively high $0.3 \mathrm{wt} . \% \mathrm{C}$. The decrease in hardness with slower cooling rates can be explained by self-tempering of martensite below $\mathrm{M}_{\mathrm{s}}$. As suggested by Gramlich et al. [23], the reduction in soluted $C$ in the matrix due to the diffusion of $C$ to lattice defects might be a reason for lower martensite hardness. The same effect was observed by Sackl et al. [24] by atom-probe tomography analysis on 42CrMo4.

The deviation of the expected cooling rates starting at $200^{\circ} \mathrm{C}$ (Figure 4) can be explained by the martensitic tranformation being exothermic. For the fastest coolings, the dilatometer control cannot respond quickly enough to the change in heat. It is notable that the start of the deviation does not correspond with $\mathrm{M}_{\mathbf{s}}$. Taking into account Figure 5, it can be seen that the formation rate of the martensitic phase is not linear and it is still low shortly below $\mathrm{M}_{\mathrm{s}}$. The start of the deviation matches with the region of maximum martensitic formation rate.

A comparison of experimental and simulated results displays that the transformation temperatures from the simulation were significantly lower than those from the experimental tests. The reason for this is the dependence of the transformation temperatures on the thermal kinetics, which were not taken into account in the equilibrium simulation. To ensure full austenitization, the homogenization temperature was therefore set to $840^{\circ} \mathrm{C}$ for the following heat treatments.

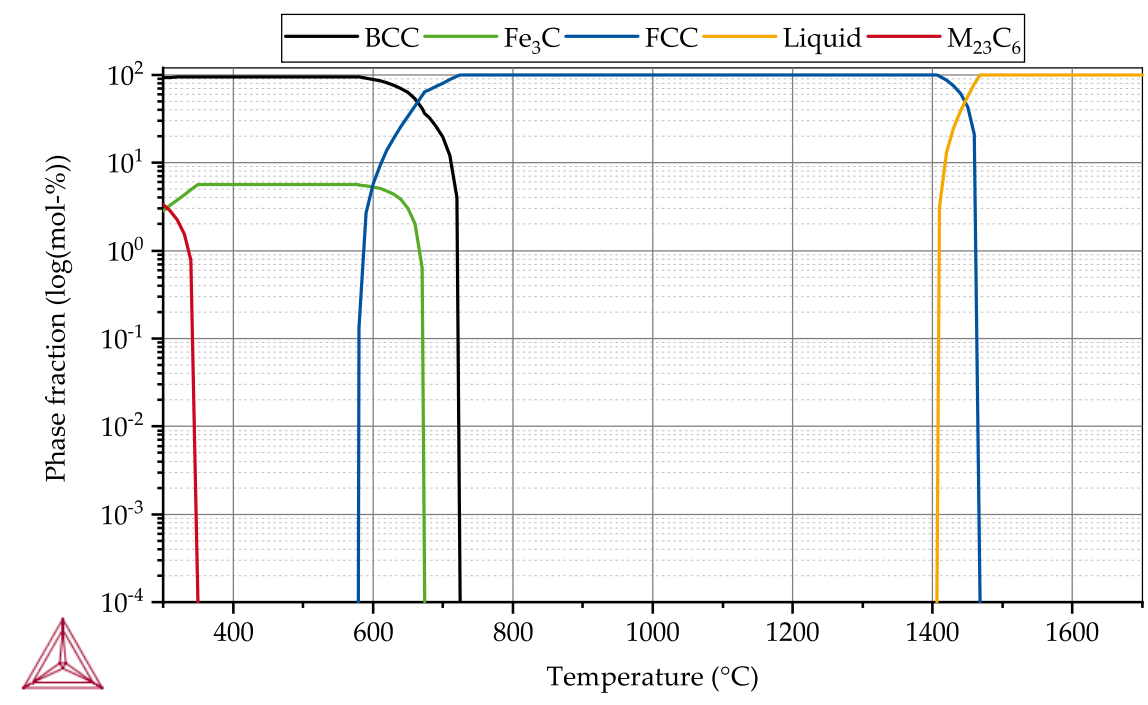

Figure 3. Thermocalc simulation of most stable phases for Fe- $0.3 \% \mathrm{C}-5 \% \mathrm{Mn}-1.5 \% \mathrm{Si}$.

The $M_{s}$ temperature showed no dependence of the cooling rate in the investigated range and was determined to be $244^{\circ} \mathrm{C}$ which was in very good agreement with the empiric equation for $M_{s}$ as suggested by Andrews [25]:

$$
M_{S}=539.0-423.0 \times \mathrm{C}-30.4 \times \mathrm{Mn}-12.1 \times \mathrm{Cr}-17.7 \times \mathrm{Ni}-7.5 \times \mathrm{Mo}+10.0 \times \mathrm{Co}-7.5 \times \mathrm{Si}
$$

The martensitic transformation was completed at $85^{\circ} \mathrm{C}$.

To estimate the martensitic phase fractions in dependence of $T_{Q}$, the K-M equation (Equation (1)) [22] as well as adaptions of it by Seo et al. [26] and van Bohemen and Sietsma [27] were applied to the here-studied material and compared to the experimental results of dilatometry (Figure 5, Equation (2)). For $M_{s}$, an experimentally determined value of $244^{\circ} \mathrm{C}$ was applied. The comparison shows that for medium manganese steels, further adaptions of the equation are needed. Hence, an adjusted $\mathrm{K}-\mathrm{M}$ equation was empirically determined for $\mathrm{Fe}-0.3 \% \mathrm{C}-5 \% \mathrm{Mn}-1.5 \% \mathrm{Si}$ based on dilatometric data of martensitic transformed as-quenched samples:

$$
V_{m}=1-\exp \left(-0.00203\left(M_{s}-T_{Q}\right)^{1.54765}\right)
$$


According to Equation (4), the martensite phase fraction was $99.4 \%$, reaching the dilatometrically determined $M_{f}$ of $85^{\circ} \mathrm{C}$. For room temperature, a phase fraction of $99.98 \%$ was calculated, which was in very good agreement with EBSD measurements of as-quenched samples detecting only $0.02 \%$ of the fcc phase.

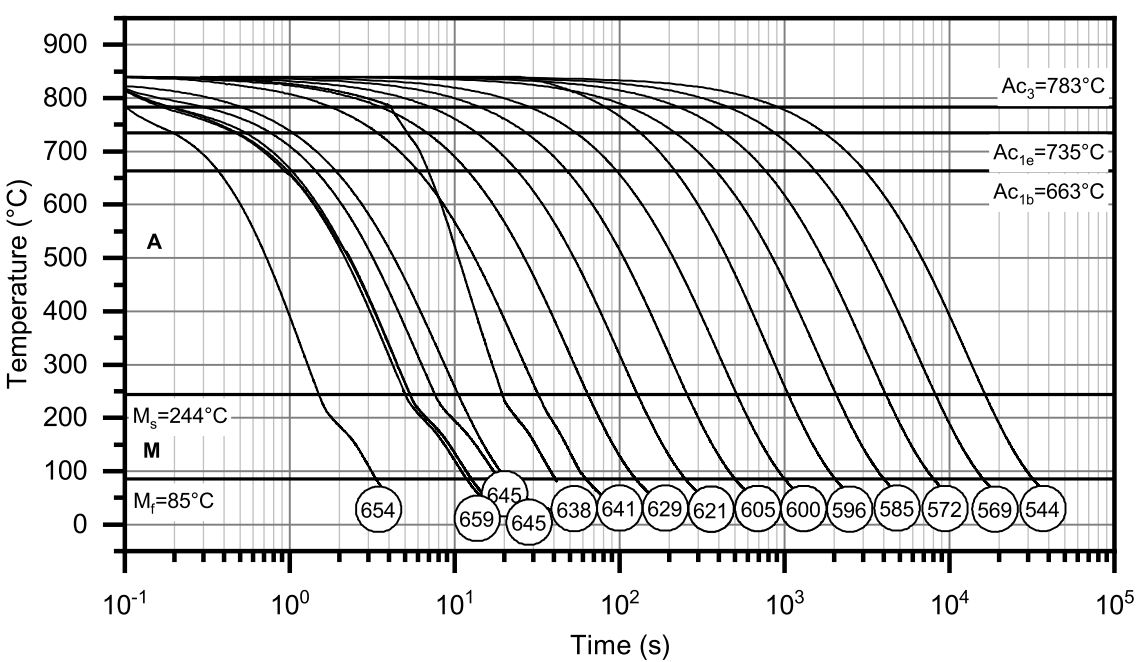

Figure 4. Experimentally determined CCT-diagram for an austenitization time of $300 \mathrm{~s}$ at $840{ }^{\circ} \mathrm{C}$ (hardness HV30).

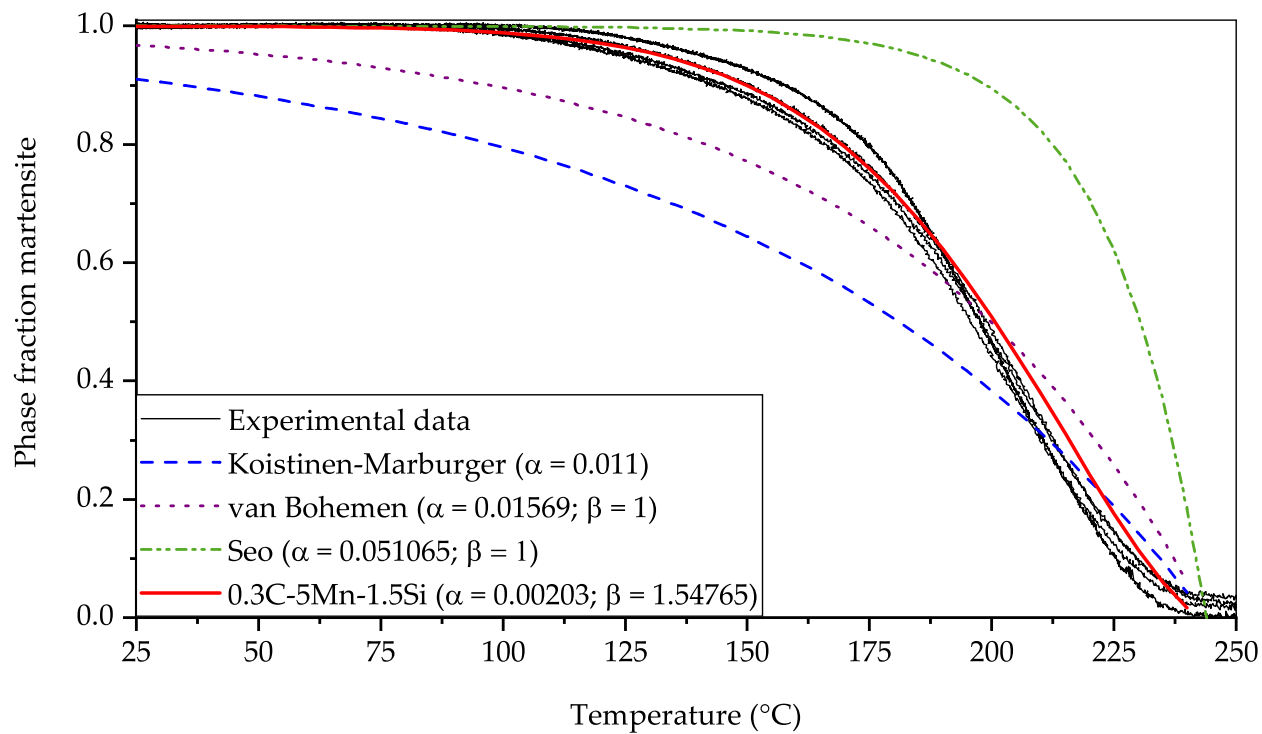

Figure 5. Experimental and empirical determination of primary martensite's phase fraction in dependence of $T_{Q}$.

In the cold-rolled condition, Fe- $0.3 \% \mathrm{C}-5 \% \mathrm{Mn}-1.5 \% \mathrm{Si}$ showed a martensitic microstructure with a pronounced rolling texture (Figure 6a). The combination of thermodynamic simulation, dilatometric tests, and EDX measurement suggests that the bright particles in Figure $6 \mathrm{~b}$ are carbides. During homogenization at $840^{\circ} \mathrm{C}$ for $300 \mathrm{~s}$, the carbides dissolve $\left(\mathrm{A}_{\mathrm{c} 1 \mathrm{e}}=735^{\circ} \mathrm{C}\right)$, and the microstructure is fully austenitic with an average grain size of $9 \mu \mathrm{m}$ (measured as prior austenite grain size). The subsequent quenching to room temperature suppresses further diffusion processes and leads to a fully martensitic microstructure (Figure 6d) with higher dissolved C-content, as in the cold-rolled state, corresponding to a greater lattice distortion [28]. 
While the cold-rolled samples have a tensile strength of $1340 \mathrm{MPa}$ and a total elongation of $2.7 \%$, the as-quenched specimens fail early during tensile testing without any plastic deformation (Figure $6 c, e$ ). The fracture surface of these as-quenched samples shows an intergranular fracture along the prior austenite grain boundaries, which is what might be related to embrittlement due to segregations. Nasim et al. [29] attribute the occurrence of intergranular fracture in an as-quenched $8 \mathrm{wt} \% \mathrm{Mn}$ steel to the enrichment of especially $\mathrm{N}$ on prior austenite grain boundaries. Given the low $\mathrm{N}$ content in the here-studied laboratory-produced material, embrittlement due to Mn and P segregations during hot rolling, homogenization, and air cooling, as suggested by Han et al. [30], seems to be more probable. Brittle intergranular fracture of fully martensitic steel due to Mn segregations on prior austenite grain boundaries was also stated by Kuzmina et al. [31]. Solute decohesion and changes in the magnetic effects ( $\mathrm{Mn}$ is more electronegative than $\mathrm{Fe}$ ), which diminish the metal-metal bond, are mentioned as a possible explanation. To reduce embrittlement, they [31] suggested an intercritical annealing prior to a tempering treatment causing austenite to form at the Mn segregations.

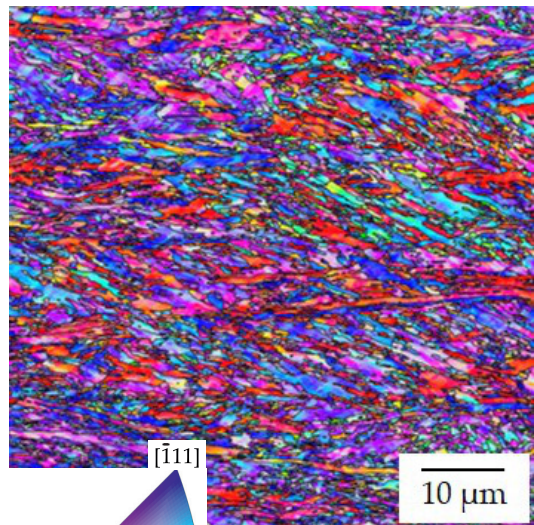

(a)

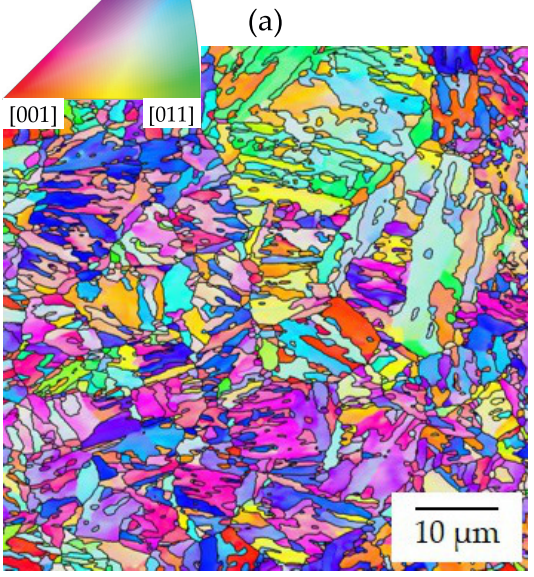

(d)

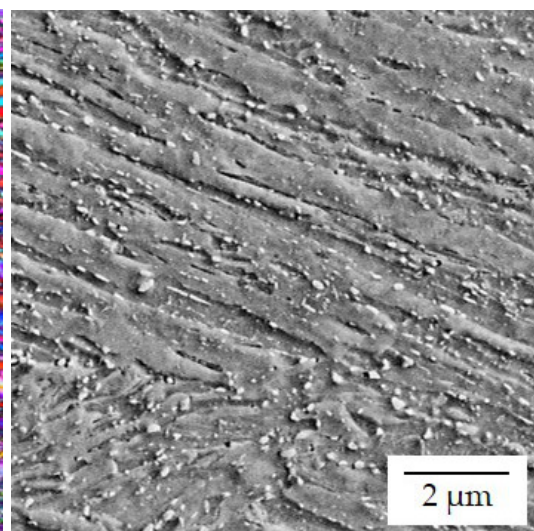

(b)

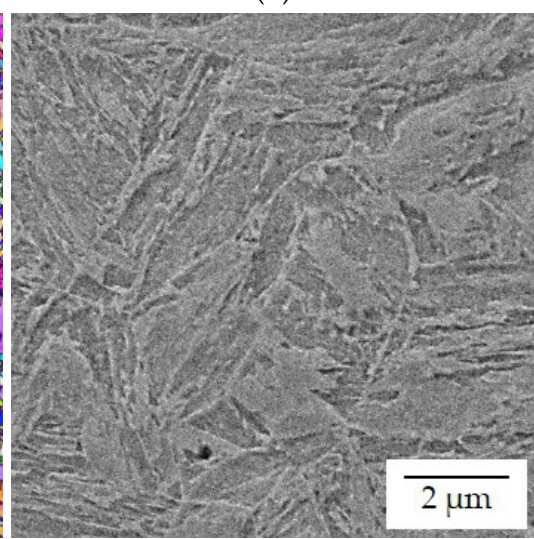

(e)

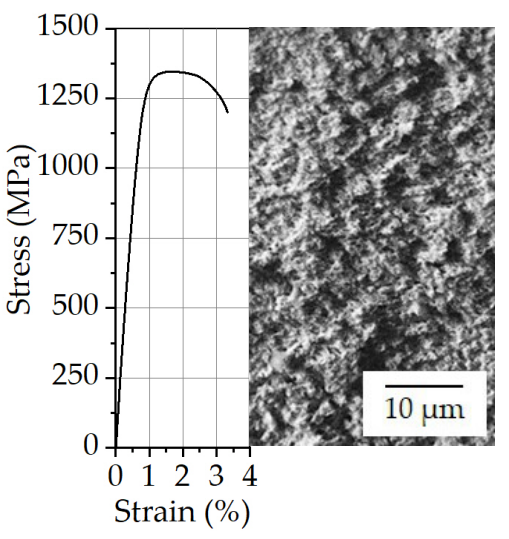

(c)

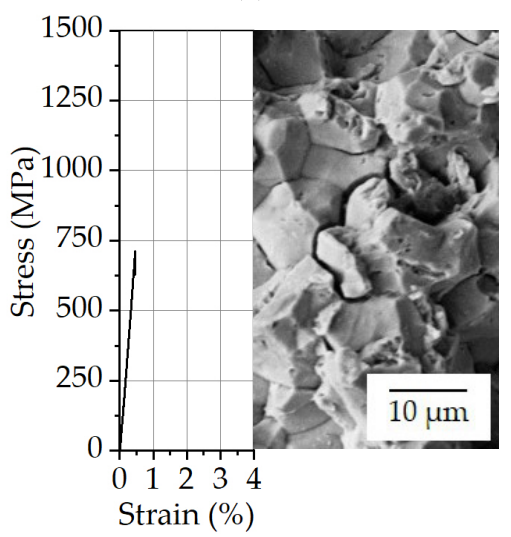

(f)

Figure 6. (a) IPF map of the cold-rolled state; (b) SEM image of the cold-rolled state containing small carbides; (c) tensile test results in combination with phase map (blue $=\mathrm{bcc}$ ) and fracture surface of the cold-rolled state; (d) IPF map of the as-quenched state; (e) SEM image of the martensitic as-quenched state; (f) tensile test results in combination with phase map (blue $=$ bcc) and fracture surface of the as-quenched state.

\subsection{Quenching \& Partitioning}

\subsubsection{Influence of $T_{Q}$}

The microstructure of the samples quenched to $150-210{ }^{\circ} \mathrm{C}$ followed by a partitioning treatment at $400{ }^{\circ} \mathrm{C}$ for $60 \mathrm{~s}$ consists of primary (tempered) martensite (low C content), secondary martensite (high $\mathrm{C}$ content), and retained austenite. The phase fraction of primary martensite increases, and correspondingly the austenite fraction decreases after 
first quenching with decreasing $T_{Q}$. The dilatometric investigation on Fe- $0.3 \% \mathrm{C}-5 \% \mathrm{Mn}-$ $1.5 \% \mathrm{Si}$ shows that the amount of primary martensite is hereby, especially between 170 $210{ }^{\circ} \mathrm{C}$, very sensitive to $T_{Q}$ due to fast martensite transformation kinetics, which is also illustrated in Figure 5.

During subsequent partitioning treatment at $400^{\circ} \mathrm{C}$, Speer et al. [32] suppose with their constrained carbon equilibrium model that $C$ diffuses from primary martensite into the remaining austenite assuming that no competing reactions like bainite or carbide formation occur $[32,33]$. Accordingly, the higher $C$ content stabilizes the austenite by lowering the $M_{s}$. The occurrence of carbides during partitioning in the here-studied material could be excluded following the microstructure analysis. Additionally, a possible bainite formation during partitioning was ruled out, since no significant change in length over the holding time at $400{ }^{\circ} \mathrm{C}$ was detected by means of dilatometry. Hence, the carbon was used entirely for the stabilization of the austenite. Despite this, the chosen partitioning treatment for samples quenched to $T_{Q} \geq 150{ }^{\circ} \mathrm{C}$ was not sufficient to lower $M_{S}$ to room temperature; hence, secondary martensite started to form out of the carbon enriched austenite during final quenching. Thus, the retained austenite content for samples quenched to exemplary $170{ }^{\circ} \mathrm{C}$ decreased during final quenching from almost $50 \%$ to $7 \%$, resulting in $43 \%$ fresh secondary martensite.

With its higher carbon content, secondary martensite features a higher resistance to nital etching and is therefore distinguishable from primary martensite by light-optical (Figure 7d) and scanning-electron microscopy, which was also shown by the work of Santofimia et al. [34]. In a different study, Santofimia et al. [35] supposed identifying primary and secondary martensite by analyzing EBSD IQ maps. Secondary martensite with its higher carbon content should result in higher distortion and thus lower IQ than areas of tempered primary martensite. Nevertheless, a quantitative determination of primary and secondary martensite by this mean is not possible. The combined phase and IQ maps for QP130_60 and QP170_60 are presented in Figure 7c,e. Red areas describe the retained austenite (fcc), while the remaining parts of the microstructure consist of martensite with different IQ. Although formation of secondary martensite was not identified in QP130_60 by dilatometry, its IQ map shows a strong variation, which might be caused by grain boundaries or phase interfaces, which also result in poor band contrast. In comparison to QP130_60, the combination of phase and IQ map of QP170_60 shows a coarser microstructure with a lower austenite phase fraction. The microstructure consists of filmlike and blocky austenite, fine martensite laths, and martensite plates larger than $10 \mu \mathrm{m}$. Within these plates, a variation in IQ can be detected, which might be due to incomplete partitioning and therefore inhomogeneous distribution of $C$, assuming the plates are primary martensite, which is in good agreement with [35]. The finer lath martensite features a lower IQ, which might be an indication for secondary martensite.

The lower the austenite content after first quenching, the more primary martensite and thus carbon is available for the diffusion into austenite and its stabilization during partitioning $[34,36]$. Therefore, quenching to $130^{\circ} \mathrm{C}$ led to a complete stabilization of retained austenite during partitioning, and, hence, the final microstructure consisted only of primary tempered martensite and islands of retained austenite with a total phase fraction of $13 \%$.

The analysis of the corresponding dilatation curves supports the observation of the microstructure investigations and is exemplary given in Figure 7a. For samples with $T_{Q}=150-210^{\circ} \mathrm{C}$, the dilatation curves show a deviation from the linear curve during final quenching, which denotes the initiation of a secondary martensite phase transformation and, hence, is an indication of the poor thermal stability of austenite. The dependence of $M_{S}$ of secondary martensite on $T_{Q}$ is displayed in Figure 8.

Since the observed phase transformation was not completed, the $M_{f}$ was obviously set below room temperature during partitioning. For samples quenched to $130{ }^{\circ} \mathrm{C}$, no indications for a phase transformation during final cooling can be found, wherefore $M_{S}$ and $M_{f}$ have to be below room temperature. 


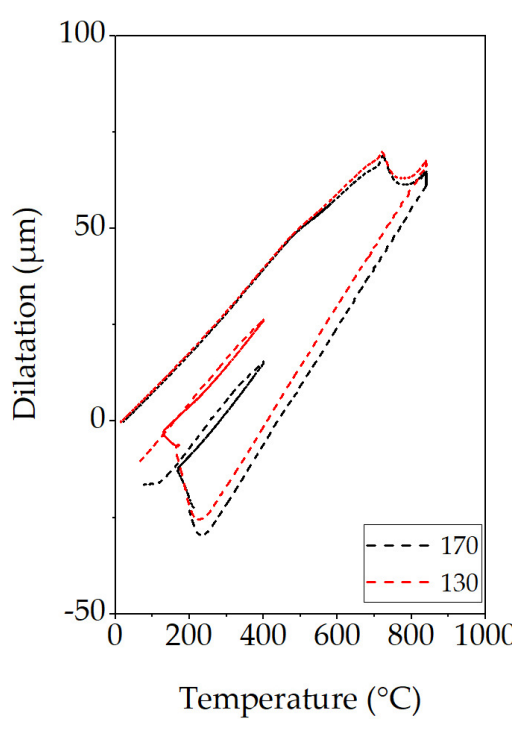

(a)

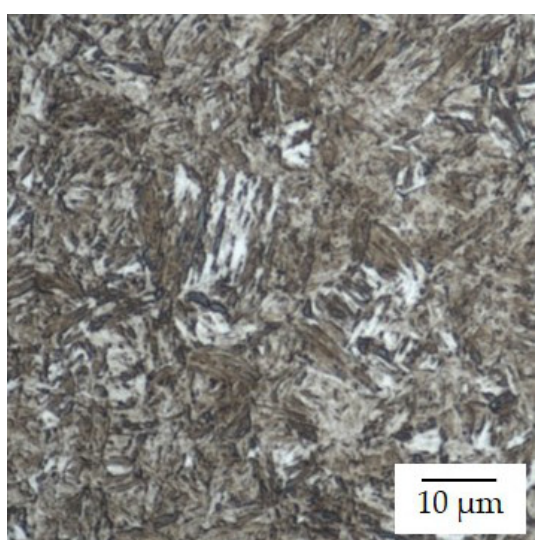

(b)

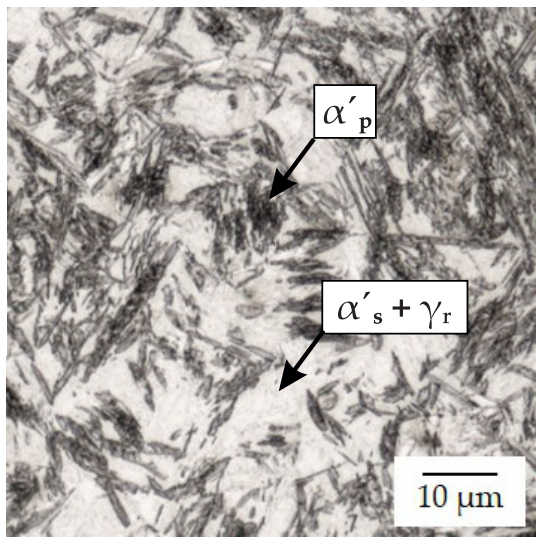

(d)

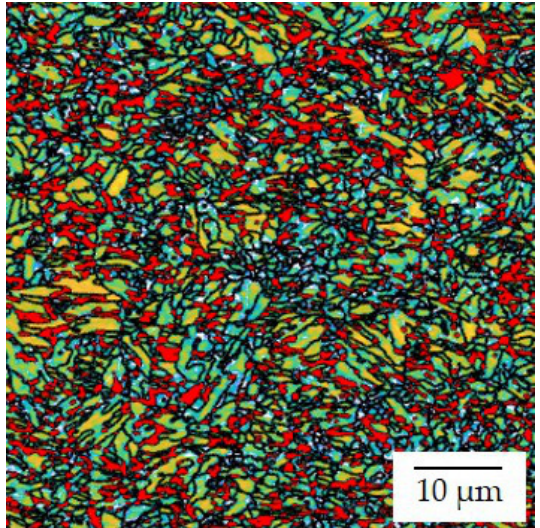

(c)

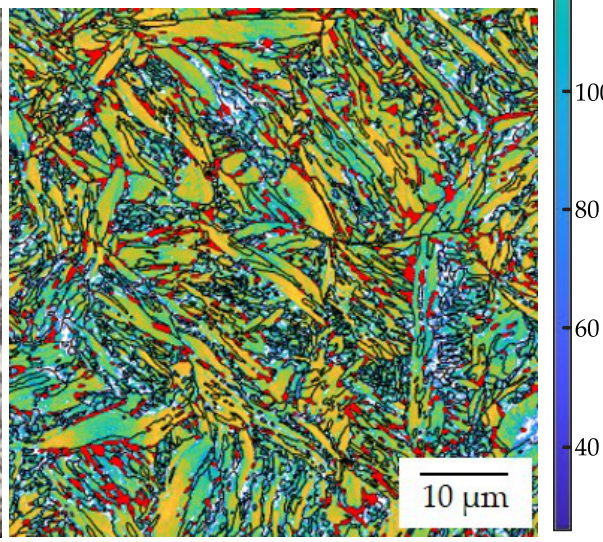

(e)

Figure 7. (a) Dilatation curves for QP170_60 and QP130_60; (b) light optical micrograph of QP130_60; (c) combination of EBSD phase map (fcc = red) and IQ map of QP130_60; (d) light optical micrograph of QP170_60 showing primary (dark) and secondary martensite (bright); (e) combination of EBSD phase map (fcc = red) and IQ map of QP170_60.

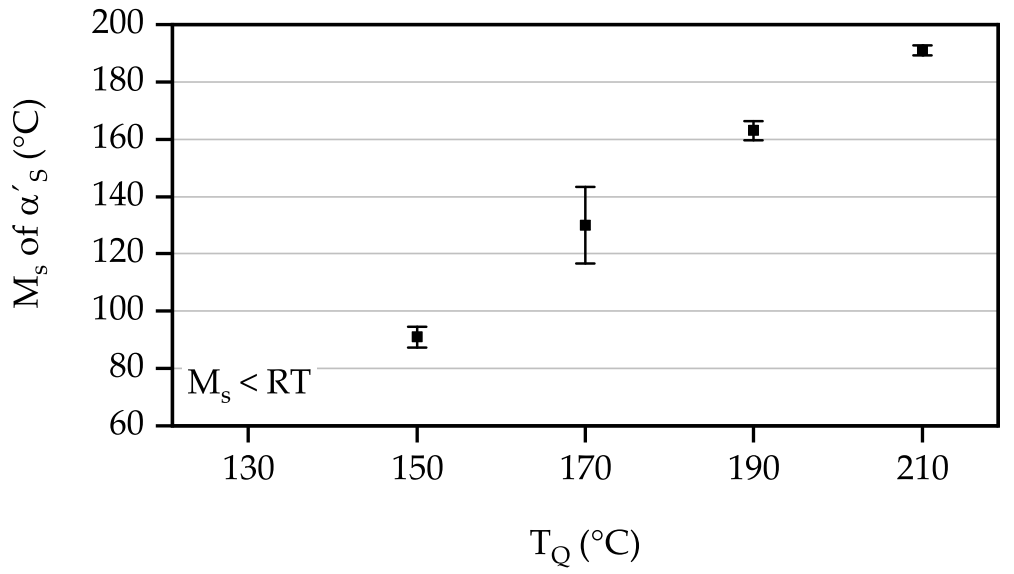

Figure 8. $M_{S}$ of secondary martensite in dependence of $T_{Q}$.

The corresponding final phase fractions determined by metallographic analysis in dependence of $\mathrm{T}_{\mathrm{Q}}$ are illustrated in Figure 9a. Retained austenite is determined by EBSD measurements, while, for primary martensite, image contrasting was used. Since it is not possible to distinguish between austenite and secondary martensite in the LOM images, the phase fraction of secondary martensite was calculated. The error bars in Figure 9a show, on the one hand, the standard deviation of the measurements of the retained austenite using EBSD (lower error bar) and, on the other hand, the standard deviation of the measurements of the primary martensite fractions using image contrasting (upper error bar). Comparing 
the results of Figure 9a with the determined phase fraction by dilatometry (Figure 5), it has to be mentioned that the phase fraction of primary martensite is underestimated by contrasting analysis. As can be seen in Figure $7 \mathrm{~b}$, primary martensite can also contain brighter areas depending on the orientation of martensite to the analyzed surface, which makes it more difficult to determine the exact phase fractions of primary and secondary martensite by image contrasting. Therfore, in-situ synchrotron X-ray diffraction was identified as a useful method for more detailed analysis of phase fractions, their composition, and transformation kinetics for future work.

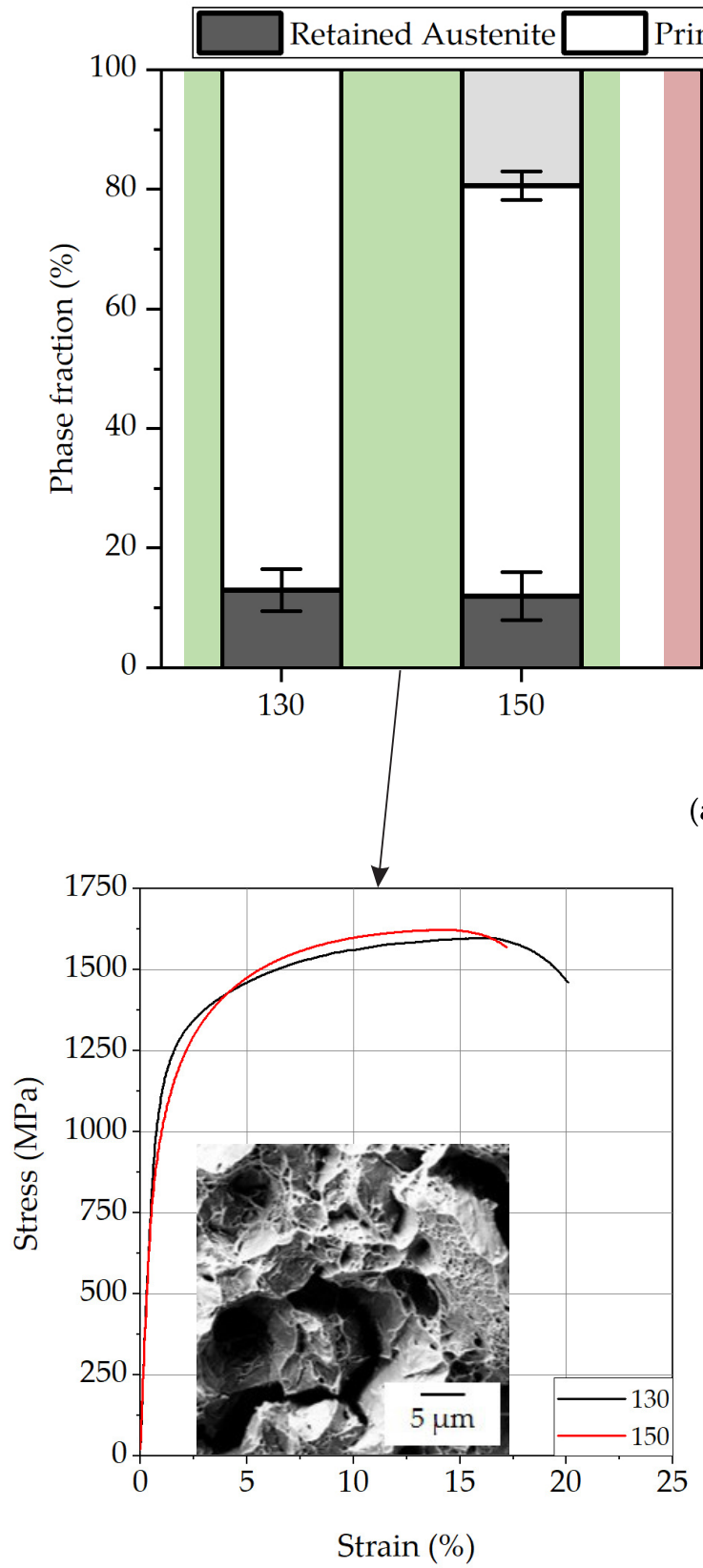

(b) (a)

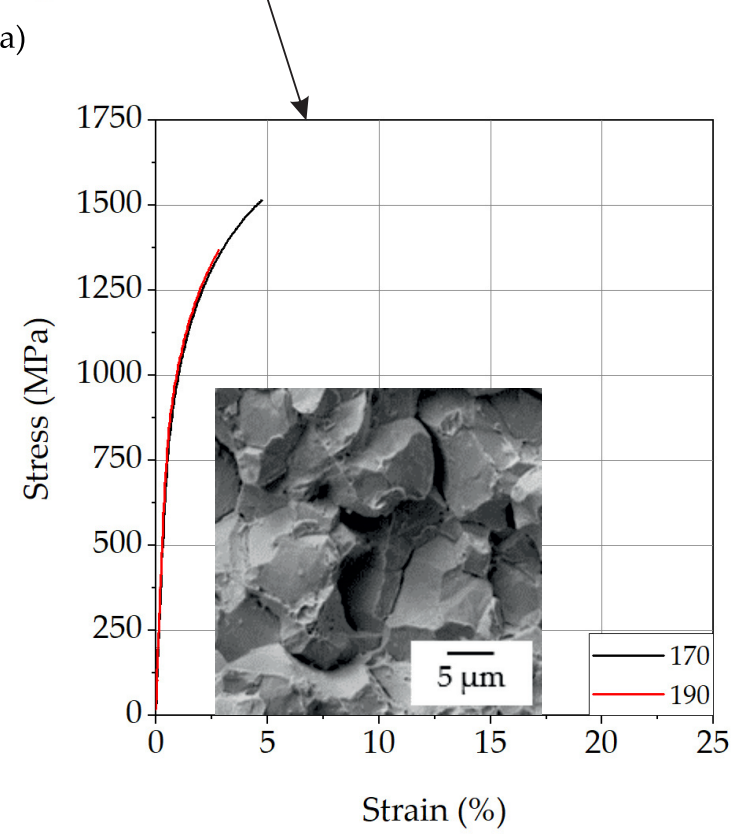

(c)

Figure 9. (a) Resulting final phase fractions in dependence of $\mathrm{T}_{\mathrm{Q}}$; (b) resulting stress-strain curves and representative fracture surface for investigated QP130_60 and QP150_60; and (c) resulting stress-strain curves and representative fracture surface for investigated QP170_60 and QP190_60.

Tensile testing revealed an excellent combination of strength and ductility for samples containing up to $13 \%$ retained austenite and $<20 \%$ fresh martensite due to quenching 
to $130^{\circ} \mathrm{C}\left(\mathrm{R}_{\mathrm{m}}=1598 \mathrm{MPa}, \mathrm{A}_{\mathrm{x}}=19.1 \%\right)$ and $150^{\circ} \mathrm{C}\left(\mathrm{R}_{\mathrm{m}}=1644 \mathrm{MPa}, \mathrm{A}_{\mathrm{x}}=16.4 \%\right)$. In comparison, $T_{Q} \geq 170{ }^{\circ} \mathrm{C}$ with a maximum of $7 \%$ retained austenite fraction and more than $40 \%$ untempered secondary martensite led to no significant increase in the ductility compared to the as-quenched state (Figures 6 and 9). This observation is in good agreement with the studies of Paravicini Bagliani et al. [37], who found a degradation of the mechanical properties of Q \& P-treated medium-carbon steels with increasing secondary martensite content up to $35 \%$. Comparable to the present study, the best combination of strength and ductility was reached with a maximum retained austenite fraction and the lowest fraction of secondary martensite.

\subsubsection{Influence of $t_{P}$}

According to the results above, the limiting values of $T_{Q}, 150$ and $170{ }^{\circ} \mathrm{C}$, were chosen to investigate the influence of a longer partitioning time on the austenite stability and the mechanical properties. EBSD measurements for $T_{Q}=150{ }^{\circ} \mathrm{C}$ showed that increasing the partitioning time from 60 to $180 \mathrm{~s}$ led to a final austenite fraction of $17 \%$. A further extension of the partitioning time up to $300 \mathrm{~s}$ raised the retained austenite content even to $21 \%$ (Figure 10). A comparison of the dilatation curves confirms that an increased partitioning time stabilizes a higher retained austenite content, which was set after the first quenching to $150{ }^{\circ} \mathrm{C}$, and hence less fresh secondary martensite formed. While after a partitioning of $60 \mathrm{~s}$, secondary martensite starts to form during quenching to room temperature at $91^{\circ} \mathrm{C}$, this temperature was set below $60^{\circ} \mathrm{C}$ for samples with previous partitioning for $300 \mathrm{~s}$. Even after $300 \mathrm{~s}$ of partitioning, microstructure analysis revealed no carbides and no bainite formation.

With respect to the mechanical properties, the increased partitioning time led only to a moderately higher uniform and total elongation at a comparable strength level (Table 2). The only slight influence of partitioning time at $400{ }^{\circ} \mathrm{C}$ on the elongation was also stated by Arlazarov et al. [38], who investigated 0.29 wt $\%$ C-3 wt $\% \mathrm{Mn}-1.4 \mathrm{wt} \% \mathrm{Si}$ steel.

Table 2. Mechanical properties in dependence of tp for $T_{Q}=150{ }^{\circ} \mathrm{C}$ and $170{ }^{\circ} \mathrm{C}$.

\begin{tabular}{cccccc}
\hline $\boldsymbol{T}_{\boldsymbol{Q}}\left({ }^{\circ} \mathbf{C}\right)$ & $\mathbf{t}_{\mathbf{P}}(\mathbf{s})$ & $\left.\mathbf{R}_{\mathbf{p 0 . 2}} \mathbf{( M P a}\right)$ & $\mathbf{R}_{\mathbf{m}} \mathbf{( M P a )}$ & $\mathbf{A}_{\mathbf{g}}(\mathbf{\%})$ & $\mathbf{A}_{\mathbf{x}}(\mathbf{\%})$ \\
\hline \multirow{2}{*}{150} & 60 & 923 & 1634 & 13.0 & 16.3 \\
& 180 & 950 & 1648 & 15.3 & 18.8 \\
& 300 & 946 & 1640 & 15.0 & 18.8 \\
\hline \multirow{2}{*}{170} & 60 & 912 & 1515 & 3.8 & 3.8 \\
& 180 & 892 & 1508 & 5.0 & 5.0 \\
& 300 & 878 & 1471 & 3.7 & 3.7 \\
\hline
\end{tabular}

In the case of quenching to $170{ }^{\circ} \mathrm{C}$, even prolonged partitioning from $60 \mathrm{~s}$ up to $300 \mathrm{~s}$ did not stabilize much more austenite. The dilatation curves show that even after $300 \mathrm{~s}$ of partitioning, $M_{\mathcal{S}}$ was still about $135^{\circ} \mathrm{C}$; thus, $37.1 \%$ hard secondary martensite formed during final quenching. The final austenite content raised slightly from 7 to $11 \%$. Within this test series, no significant differences in the strength and ductility properties can be achieved. Compared to the samples quenched to $150^{\circ} \mathrm{C}$, the samples also showed a relatively high strength level but no plastic deformation (Table 2). 


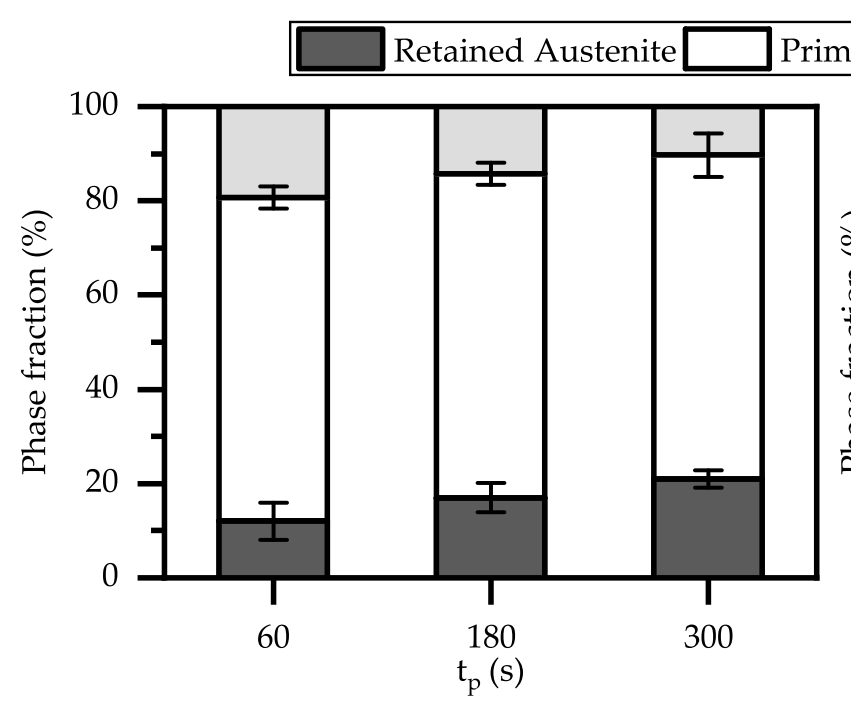

(a)

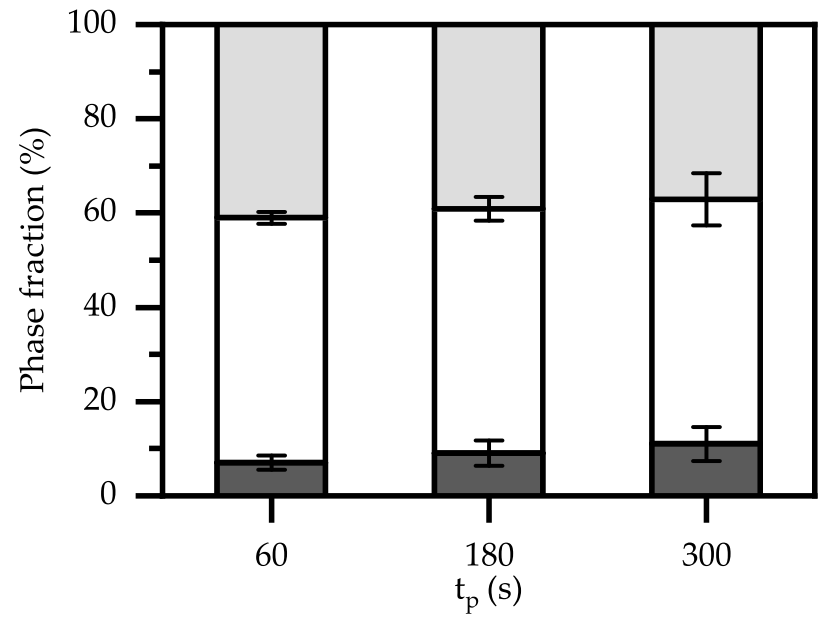

(b)

Figure 10. Final phase fractions in dependence of tp for $(\mathbf{a}) T_{Q}=150{ }^{\circ} \mathrm{C}$ and $(\mathbf{b}) T_{Q}=170{ }^{\circ} \mathrm{C}$.

\subsubsection{Role of Secondary Martensite on Ductility}

Comparing the mechanical properties of QP170_300 to QP130_60 with a similar austenite content in the range of $11-13 \%$, it is worth mentioning that the stable austenite content after final quenching cannot be solely responsible for the good ductility of samples quenched to $T_{Q}=130{ }^{\circ} \mathrm{C} / 150^{\circ} \mathrm{C}$. Another ductility-determining factor is the increasing fraction of secondary martensite, which leads to an increasing probability of crack formation and propagation [39]. While there is no secondary martensite and a total elongation of $19.1 \%$ in samples QP130_60, the amount of secondary untempered martensite in samples QP170_300 reaches 37\%, and the total elongation decreases to 3.7\%.

In Figure 11, the predominantly brittle fracture surface of QP170_300 is shown. Small ductile areas are marked with black arrows (Figure 11a) and can be assigned austenite. Although a quantitative analysis of the $C$ content by EDX measurement is not possible, the qualitative comparison of the $\mathrm{C}$ content suggests that the existing cracks perpendicular to the fracture surface might run between primary martensite with relatively low $C$ content and secondary martensite with approximately $2.5 \times$ higher $C$ content (Figure $11 \mathrm{~b}$ ).

In this context, De Knijf et al. [40] detected after Q \& P treatment and successive tensile testing deformed areas of primary martensite but no deformation in fresh martensite areas that led to a high stress concentration in its surroundings and hence void formation on primary/secondary martensite interface leading to early fracture of the material, which was also found in the present study (Figure 9a,c). Wang et al. [41] also identified in their studies on Fe-0.3C-2.5Mn-1.5Si-0.8Cr (wt $\%$ ) micro-cracks, which form due to strain localization in the vicinity of coarse martensite laths and untempered fresh martensite. A homogeneous distribution of austenite islands in the microstructure reduces the localization of the strain and promotes homogeneous plastic deformation even in the martensitic matrix [41]. To minimize secondary martensite fraction and to retain a maximum fraction of austenite, Celada-Casero et al. [42] determined an optimum primary martensite fraction of $\geq 77 \%$ to ensure complete $\mathrm{C}$ partitioning to austenite during partitioning at $400{ }^{\circ} \mathrm{C}$ for $50 \mathrm{~s}$, which is in good agreement with the present results shown in Figure 9a,b. Comparing Figure 9, Figure 10, and Table 2, the maximum tolerable secondary martensite amount that still enables good ductility was found to be $20 \%$. 


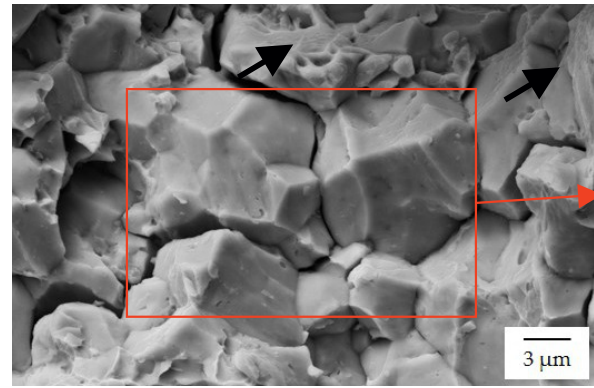

(a)

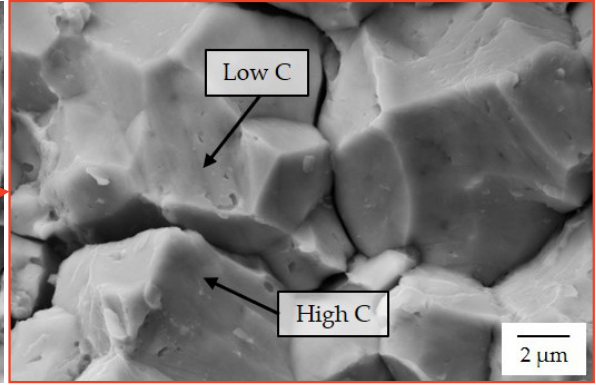

(b)

Figure 11. (a) Mainly brittle intergranular fracture surface of QP170_300 tensile test sample containing small ductile areas and cracks; (b) crack running between microstructural areas with relatively low and high $\mathrm{C}$ content measured by EDX.

\section{Conclusions}

An extensive dilatometer study in combination with a microstructure analysis to check the reproducibility of the suggested heat treatments on tensile specimens allowed to define a suitable process window for the $\mathrm{Q} \& \mathrm{P}$ process of Fe- $0.3 \% \mathrm{C}-5 \% \mathrm{Mn}-1.5 \% \mathrm{Si}$. To predict the phase fraction of primary martensite in dependence of $T_{Q}$, an adjustment of the $\mathrm{K}-\mathrm{M}$ equation was suggested for the medium manganese steel.

While the as-quenched condition failed in a brittle way and is therefore less suitable for direct press-hardening application without additional heat treatment, Q \& P was used to significantly increase the ductility of the investigated material. However, $12-21 \%$ austenite only results in good ductility provided that the formation of secondary martensite is suppressed as far as possible.

High levels of secondary martensite, despite an austenite content of $11 \%$, have a detrimental effect on the mechanical properties and lead to early failure. However, the study identified an amount of up to $20 \%$ secondary martensite as uncritical, which extends the optimum $\mathrm{T}_{\mathrm{Q}}$ from $130^{\circ} \mathrm{C}$ to a range of $130-150^{\circ} \mathrm{C}$, providing a wider margin for engineering application.

The influence of the partitioning duration can be considered minor. The good combination of properties can already be achieved after a short partitioning, which is particularly advantageous for throughput in industry. If technical problems result in a longer partitioning time (up to $300 \mathrm{~s}$ ), the component still exhibits comparable properties and can be used.

Author Contributions: Conceptualization, C.B.; methodology, C.B.; validation, C.B.; formal analysis, C.B.; investigation, C.B.; data curation, C.B.; writing-original draft preparation, C.B.; writingreview and editing, C.B., S.W., and U.K.; visualization, C.B.; supervision, S.W. and U.K.; project administration, S.W.; funding acquisition, U.K. All authors have read and agreed to the published version of the manuscript.

Funding: This research was funded by the Deutsche Forschungsgemeinschaft (DFG, German Research Foundation) under Germany's Excellence Strategy_EXC-2023 Internet of Production.

Institutional Review Board Statement: Not applicable.

Informed Consent Statement: Not applicable.

Data Availability Statement: The data presented in this study are available on request from the corresponding author.

Acknowledgments: The authors gratefully acknowledge the support of H. Breitbach and M. Schillheim, in mechanical testing and dilatometry experiments. Special thanks are given to R. Emmrich and A. Gramlich for reviewing and for fruitful discussions.

Conflicts of Interest: The authors declare no conflict of interest. 


\section{References}

1. Schmitt, J.H.; Iung, T. New developments of advanced high-strength steels for automotive applications. Comptes Rendus Phys. 2018, 19, 641-656. [CrossRef]

2. Bleck, W.; Brühl, F.; Ma, Y.; Sasse, C. Materials and Processes for the Third-generation Advanced High-strength Steels. BHM BergHüttenmännische Monatshefte 2019, 164, 466-474. [CrossRef]

3. Neugebauer, R.; Schieck, F.; Polster, S.; Mosel, A.; Rautenstrauch, A.; Schönherr, J.; Pierschel, N. Press hardening-An innovative and challenging technology. Arch. Civ. Mech. Eng. 2012, 12, 113-118. [CrossRef]

4. Järvinen, H.; Isakov, M.; Nyyssönen, T.; Järvenpää, M.; Peura, P. The effect of initial microstructure on the final properties of press hardened 22MnB5 steels. Mater. Sci. Eng. A 2016, 676, 109-120. [CrossRef]

5. Karbasian, H.; Tekkaya, A.E. A review on hot stamping. J. Mater. Process. Technol. 2010, 210, 2103-2118. [CrossRef]

6. Lenze, F.-J.; Sikora, S. Device and Method for the Forming of Blanks from High and Very High Strength Steels. U.S. Patent US9,068,239 B2, 30 June 2015.

7. Ademaj, A. Method and Device for Producing a Press-Hardened Metal Component. European Patent EP2864506B1, 11 July 2018.

8. Wang, C.; Li, X.; Han, S.; Zhang, L.; Chang, Y.; Cao, W.; Dong, H. Warm Stamping Technology of the Medium Manganese Steel. Steel Res. Int. 2018, 89, 1700360. [CrossRef]

9. Rana, R.; Carson, C.H.; Speer, J. Ductile Ultra High Strength Medium Manganese Steel Produced through Continuous Annealing and Hot Stamping. U.S. Patent Application Publication US2016/0312323 A1, 27 October 2016.

10. Oh, J.-K.; Lee, K.-Y.; Cho, Y.-R.; Choi, E.-Y.; Kim, K.-S. Steel Sheet for Warm Press Forming, Warm Press Formed Parts and Method for Manufacturing Thereof. European Patent Application Publication EP2778247 A1, 17 September 2014.

11. Wang, Z.; Zhang, Y.; Zhu, B.; Wang, Y.; Ding, H.; Cai, M. Hot stamped parts with desirable properties in medium Mn TRIP steels. Procedia Eng. 2017, 207, 699-704. [CrossRef]

12. Wang, Z.; Liu, P.; Xu, Y.; Wang, Y.; Zhang, Y. Hot Stamping of High Strength Steel with Tailored Properties by Two Methods. Procedia Eng. 2014, 81, 1725-1730. [CrossRef]

13. Merklein, M.; Franke, J.M.; Geiger, M.; Schmidt, M., Eds. Ein Ansatz zur Herstellung von Pressgehärteten Karosseriekomponenten mit Maßgeschneiderten Mechanischen Eigenschaften: Temperierte Umformwerkzeuge. Prozessfenster, Prozesssimulation und Funktionale Untersuchung; Fertigungstechnik-Erlangen, Meisenbach: Bamberg, Germany, 2012; Volume Bd.226,

14. Merklein, M.; Wieland, M.; Lechner, M.; Bruschi, S.; Ghiotti, A. Hot stamping of boron steel sheets with tailored properties: A review. J. Mater. Process. Technol. 2016, 228, 11-24. [CrossRef]

15. Tong, C.; Rong, Q.; Yardley, V.A.; Li, X.; Luo, J.; Zhu, G.; Shi, Z. New Developments and Future Trends in Low-Temperature Hot Stamping Technologies: A Review. Metals 2020, 1652, 1652. [CrossRef]

16. Meza-García, E.; Rautenstrauch, A.; Bräunig, M.; Kräusel, V.; Landgrebe, D. Energetic evaluation of press hardening processes. Procedia Manuf. 2019, 33, 367-374. [CrossRef]

17. Chang, Y.; Wang, C.Y.; Zhao, K.M.; Dong, H.; Yan, J.W. An introduction to medium-Mn steel: Metallurgy, mechanical properties and warm stamping process. Mater. Des. 2016, 94, 424-432. [CrossRef]

18. Speer, J.; Rana, R.; Matlock, D.; Glover, A.; Thomas, G.; de Moor, E. Processing Variants in Medium-Mn Steels. Metals 2019, 9, 771. [CrossRef]

19. Seo, E.J.; Cho, L.; de Cooman, B.C. Application of Quenching and Partitioning (Q\&P) Processing to Press Hardening Steel. Metall. Mater. Trans. A 2014, 45, 4022-4037. [CrossRef]

20. de Cooman, B.C.; Lee, S.J.; Shin, S.; Seo, E.J.; Speer, J.G. Combined Intercritical Annealing and Q\&P Processing of Medium Mn Steel. Metall. Mater. Trans. A 2017, 48, 39-45. [CrossRef]

21. de Moor, E.; Speer, J.G.; Matlock, D.K.; Kwak, J.H.; Lee, S.B. Effect of Carbon and Manganese on the Quenching and Partitioning Response of CMnSi Steels. ISIJ Int. 2011, 51, 137-144. [CrossRef]

22. Koistinen, D.P.; Marburger, R.E. A general equation prescribing the extent of the austenite-martensite transformation in pure iron-carbon alloys and plain carbon steels. Acta Metall. 1959, 7, 59-60. [CrossRef]

23. Gramlich, A.; van der Linde, C.; Ackermann, M.; Bleck, W. Effect of aluminum, molybdenum and boron on the phase transformation in 4 wt.-\% manganese steels. Results Mater. 2020, 8, 100-147.

24. Sackl, S.; Clemens, H.; Primig, S. Investigation of the Self Tempering Effect of Martensite by Means of Atom Probe Tomography. Pract. Metallogr. 2015, 52, 374-383. [CrossRef]

25. Andrews, K.W.. Empirical formulae for calculation of some transformation temperatures. J. Iron Steel Inst. 1965, $203,721-727$.

26. Seo, E.J.; Cho, L.; de Cooman, B.C. Modified Methodology for the Quench Temperature Selection in Quenching and Partitioning (Q\&P) Processing of Steels. Metall. Mater. Trans. A 2016, 47, 3797-3802. [CrossRef]

27. van Bohemen, S.; Sietsma, J. Martensite Formation in Partially and Fully Austenitic Plain Carbon Steels. Metall. Mater. Trans. A 2009, 40, 1059-1068. [CrossRef]

28. Xiao, L.; Fan, Z.; Jinxu, Z.; Mingxing, Z.; Mokuang, Z.; Zhenqi, G. Lattice-parameter variation with carbon content of martensite. I. X-ray-diffraction experimental study. Phys. Rev. B Condens. Matter 1995, 52, 9970-9978. [CrossRef]

29. Nasim, M.; Edwards, B.C.; Wilson, E.A. A study of grain boundary embrittlement in an Fe-8\%Mn alloy. Mater. Sci. Eng. A 2000, 281, 56-67. [CrossRef] 
30. Han, J.; Da Silva, A.K.; Ponge, D.; Raabe, D.; Lee, S.M.; Lee, Y.K.; Lee, S.I.; Hwang, B. The effects of prior austenite grain boundaries and microstructural morphology on the impact toughness of intercritically annealed medium Mn steel. Acta Mater. 2017, 122, 199-206. [CrossRef]

31. Kuzmina, M.; Ponge, D.; Raabe, D. Grain boundary segregation engineering and austenite reversion turn embrittlement into toughness: Example of a 9 wt.\% medium Mn steel. Acta Mater. 2015, 86, 182-192. [CrossRef]

32. Speer, J.; Matlock, D.K.; de Cooman, B.C.; Schroth, J.G. Carbon partitioning into austenite after martensite transformation. Acta Mater. 2003, 51, 2611-2622. [CrossRef]

33. Toji, Y.; Matsuda, H.; Herbig, M.; Choi, P.P.; Raabe, D. Atomic-scale analysis of carbon partitioning between martensite and austenite by atom probe tomography and correlative transmission electron microscopy. Acta Mater. 2014, 65, 215-228. [CrossRef]

34. Santofimia, M.J.; Zhao, L.; Petrov, R.; Kwakernaak, C.; Sloof, W.G.; Sietsma, J. Microstructural development during the quenching and partitioning process in a newly designed low-carbon steel. Acta Mater. 2011, 59, 6059-6068. [CrossRef]

35. Santofimia, M.J.; Petrov, R.H.; Zhao, L.; Sietsma, J. Microstructural analysis of martensite constituents in quenching and partitioning steels. Mater. Charact. 2014, 92, 91-95. [CrossRef]

36. Qi, X.; Du, L.; Hu, J.; Misra, R.D.K. Effect of austenite stability on toughness, ductility, and work-hardening of medium-Mn steel. Mater. Sci. Technol. 2019, 35, 2134-2142. [CrossRef]

37. Paravicini Bagliani, E.; Santofimia, M.J.; Zhao, L.; Sietsma, J.; Anelli, E. Microstructure, tensile and toughness properties after quenching and partitioning treatments of a medium-carbon steel. Mater. Sci. Eng. A 2013, 559, 486-495. [CrossRef]

38. Arlazarov, A.; Bouaziz, O.; Masse, J.P.; Kegel, F. Characterization and modeling of mechanical behavior of quenching and partitioning steels. Mater. Sci. Eng. A 2015, 620, 293-300. [CrossRef]

39. HajyAkbary, F.; Sietsma, J.; Petrov, R.H.; Miyamoto, G.; Furuhara, T.; Santofimia, M.J. A quantitative investigation of the effect of Mn segregation on microstructural properties of quenching and partitioning steels. Scr. Mater. 2017, 137, 27-30. [CrossRef]

40. de Knijf, D.; Petrov, R.; Föjer, C.; Kestens, L.A. Effect of fresh martensite on the stability of retained austenite in quenching and partitioning steel. Mater. Sci. Eng. A 2014, 615, 107-115. [CrossRef]

41. Wang, M.M.; Hell, J.C.; Tasan, C.C. Martensite size effects on damage in quenching and partitioning steels. Scr. Mater. 2017, 138, 1-5. [CrossRef]

42. Celada-Casero, C.; Kwakernaak, C.; Sietsma, J.; Santofimia, M.J. The influence of the austenite grain size on the microstructural development during quenching and partitioning processing of a low-carbon steel. Mater. Des. 2019, 178, 107847. [CrossRef] 